How to cite: Dombay, Șt., Magyari-Saska, Zs. (2019) Statistical Effect of Temperature on Tourism Seasonality in Romania. 2019 "Air and Water - Components of the Environment" Conference Proceedings, Cluj-Napoca, Romania, p. 271-282, DOI: 10.24193/AWC2019_27.

\title{
STATISTICAL EFFECT OF TEMPERATURE ON TOURISM SEASONALITY IN ROMANIA
}

\author{
Ștefan DOMBA Y ${ }^{1}$, Zsolt MAGYARI-SASKA ${ }^{1}$ 的
}

DOI: $10.24193 / \mathrm{AWC2019} 27$

\begin{abstract}
Climate change is a reality which is observed not only by scientists but also by the population. In our study, we want to make a preliminary research on whether this change is reflected on tourism seasonality in Romania. Therefore, we took tourist flow and temperature data for the 35 most important touristic locations and calculated a seasonality indicator which afterward was correlated with different summarized values derived from temperature data at monthly scale. We observed that seasonality is highly related to temperature values, especially to the average of daily mean values and often this correlation value exceeds 0.8 (threshold value is 0.195 ). The high correlation values don't follow any pattern in spatial distribution. We identified that the top three places where the temperature has an increasing correlation with seasonality in the past years is Târgu-Mureș, Cluj-Napoca and Râmnicu Vâlcea. Although temperature is not the only factor influencing seasonality it seems to be a highly important one, as only for three places the Pearson correlation coefficient stands below 0.5 .
\end{abstract}

Keywords: temperature, tourism flow, seasonality, correlation

\section{INTRODUCTION}

Tourism is a socio-economic phenomenon whose development is strongly influenced by external factors on both the demand and supply side, including the climatic conditions of the destination (Gonda, 2017) for spa and wellness tourism as well (Csapo and Marton, 2017), political environment, economic development or socio-cultural characteristics (Puczkó and Rátz 2005). The description of the effects of the atmospheric environment including temperature on humans is dealt with by the human-biometeorological science (Höppe, 1997), which it began to develop dynamically from its 70 s. In the past decades, many scientists have tried to describe the role of climate in many ways (Dávid and Baros, 2006). The role of climatic factors is indisputable, e.g. Gallarza et al. (2002) considers them as the seventh ones from among the twenty factors for selecting tourist destinations. Climate as factor (which has many components including temperature) is overtaken by resident's receptiveness, landscape, cultural attractions, entertainment, price and gastronomy.

\footnotetext{
1 Babes-Bolyai University, Faculty of Geography, Gheorgheni University Extension, dombay.istvan@gmail.com zsmagyari@gmail.com
} 
In recent years, as a new line studies on the relationship between climate and tourism have also appeared. In the past bioclimatic maps were used for the assessment of the climatic conditions of each tourist destination. In this respect, the pioneers are Matsarakis and Mayer (1997). They developed a thermal stress calculation and applied it for 1980-1989 in Greece.

The aim of our study was to find whether the variations in temperature values over Romania imply a change in tourism seasonality, which also has different values in different regions of the country.

\section{DATA PREPARATION}

For data acquisition and preparation, the $\mathrm{R}$ programmable statistical system was used, developing proper script for data extraction. Two types of primary data were needed: a time series with touristic flow (tourist numbers) and several ones of temperature data.

\subsection{Extracting touristic flow data}

The source of touristic data was the TEMPO database of the Romanian National Statistical Institute (www.insse.ro). Based on automated data acquisition queries to obtain the tourist number a local series for the whole county were obtained as files on monthly resolution starting from January 2010 and ending on October 2018 (B. Economy statistics - B17 Tourism - TUR104H chapter). The individual files were pre-processed obtaining a single data frame containing both the data regarding touristic flow and national identifier values for each settlement. This latter value facilitates the geo-localization of them to extract temperature data.

\subsection{Extracting temperature data}

The temperature data were obtained as raster data, in netCDF format from www.ecad.eu. The dataset contains separate files for daily minimum, maximum and average temperatures at a 0.1-degree spatial resolution (Haylock et al., 2008), which represents an approx. $8 \times 11 \mathrm{~km}$ cell size in Romania. For current analysis, the time series with temperature data were constructed using R scripts (Pierce, 2012) just for those settlements which had at least 60,000 tourists in 2017, an average of 5,000 tourists/month.

The exact spatial location, from where the data were extracted, was based on the freely available shapefile on www.geo-spatial.org. This file also contains the settlements unique code, necessary for the join between touristic flow and locations.

The downloaded raster temperature maps contain data starting with 1950, but only the January 2010 - October 2018 period was extracted (Uddameri, 2017) corresponding to the touristic flow data range. This means that the netCDF file content was filtered both on spatial and on temporal level (Appendix 2). The daily temperature data were summarized for each month, calculating the minima, maxima and averages for each kinds of temperature, i.e. daily minimum, maximum and mean. 
As a result, we obtained a complex data frame which contains tourist number and 9 types temperature related values for the 106 months (Appendix 1). The spatial distribution of the selected location is presented in Figure 1, which covers all regions of Romania.

\section{METHODS AND DATA ANALYSIS}

The first step of data analysis was to calculate seasonality in the tourist flow and the temperature characteristics. There are several ways how to achieve this. One of the most common methods is based on Gini coefficient (eq. 1) which basically is an indicator of inequality, but can be successfully used as a seasonality indicator is described by Lundtorp (2001) and by Tsitouras (2004). The Gini coefficient was used in many studies in different regions and countries (Petrevska, 2013; Pórhallsdóttir and Ólafsson, 2017; Bigovic, 2011; Grizane, 2016). Despite it's a most common indicator for tourism seasonality is not the only one. There are several other approaches described by Karamustafa and Ulama (2010) and Corluka et al. (2018). The most important of them are seasonality ratio, seasonality indicator and seasonality share.

$$
\begin{array}{ll}
G=\frac{1}{2 \bar{x} n^{2}} \sum_{i} \sum_{j} \mid x_{i}- & x_{j} \mid \\
\text { where } & \mathrm{G} \text { is the Gini coefficient, } \\
& \mathrm{n} \text { is the number of values in series, } \\
& \mathrm{x}_{\mathrm{i}} \text { are the values. }
\end{array}
$$

In our study although we calculated the Gini coefficient, we decided to also use the monthly tourist vales divided by the year level mean as indicator for seasonality (further - relative to mean). Several publications (De Maio, 2007) argue against such simple methods like relative standard deviation (aka coefficient of variation, expressed as standard deviation divided by the mean) as being weaker indicators for seasonality as they are unbounded and expressed in original units, but there are also article which shows the importance of them (Formby et al., 1999). In our conception the unbounded state of relative to mean value helped us to clearly identify which month belongs to touristic season and which are in extra-season and also indicates the measure of inequality (higher deviation from 1 indicates more evident belongs to extra-season or season).

To prove that the temperature values in Romania for the selected period (2002018) are not stationary and has a trend we used the Mann-Kendall non-parametric trend test (Esterby, 1996; Gilbert, 1987), analysis performed both on daily values as on monthly scale summarized values.

The aim of our study was not only to identify if there are any changes in tourism seasonality for different locations in Romania, but also to examine how the changes in temperatures regime influences the seasonality of tourism, as such studies has been performed before (Kulendran and Dwyer, 2012). For this we applied standard correlation and backward stepwise multiple linear regression analysis (Myers, 1990) which can identify the most important predictors in a linear model using Akaike 
Information Criterion. All calculus of our study was made in R statistical system, using proper R packages (James et al., 2018; Zeileis and Kleiber, 2015; McLeod, 2015; Trapletti et al., 2018) and developing R script for automated analysis.

\section{RESULTS AND DISCUSSION}

As mentioned earlier the data analysis was carried out for those settlements where the annual tourist number in 2017 was at least 60000 . There were 35 such locations (Fig. 1) including the capital, Bucuresti, other 21 municipalities, 10 towns and 3 other lower rank settlements.

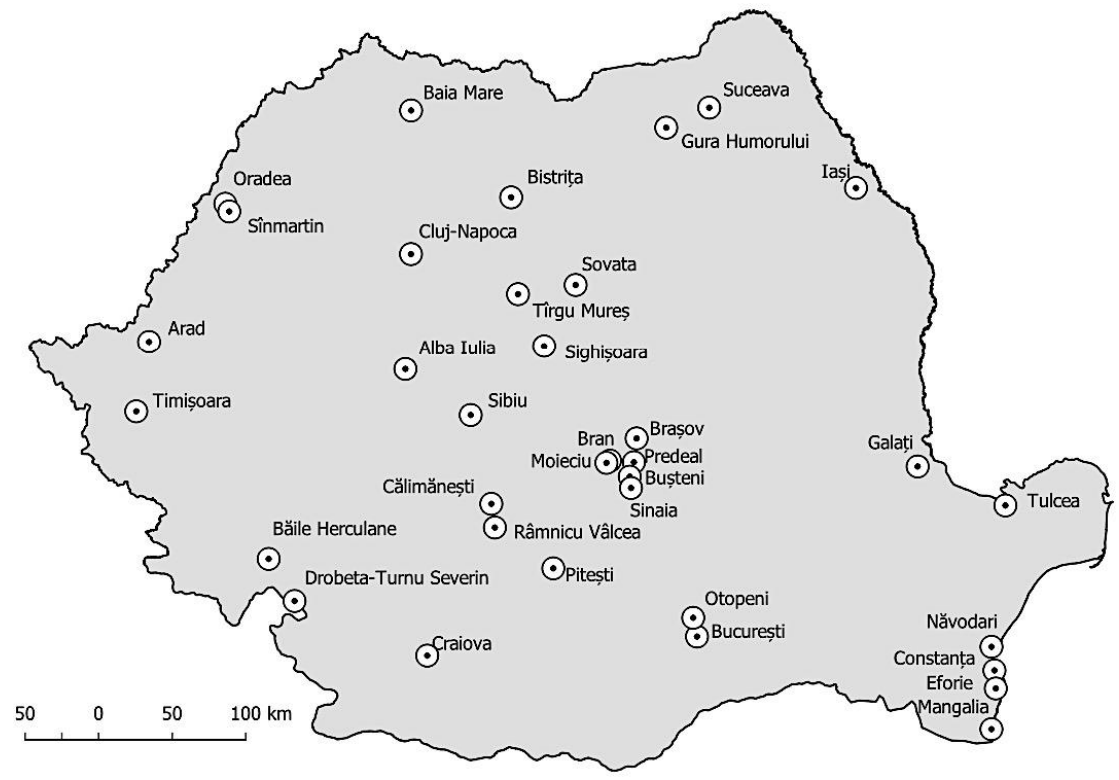

Fig. 1. Spatial distribution of selected places

The seasonality indicator was calculated for every location and for every year separately, such as same indicator values may denote different tourist flow but represents similar situations in different years regarding seasonality.

For the last 2 months in 2018 there was no values at the moment, that's why their position is used as reference values: 0 (green) and 3 (orange) times the monthly mean value.

In some cases, there is an accentuated seasonality especially for seaside settlements such as Mangalia, Constanta, Navodari or Eforie in other cases - mainly in great cities, such Bucharest, Cluj Napoca, Timisoara or Targu-Mures - seasonality is not accentual (Fig. 2).

If we look at seasonality dynamics over time, we can observe that in some cases are noticeable changes (ex. Sanmartin, Oradea, Calimanesti, Tulcea) while in others there's not (ex. Timisoara, Mangalia, Constanta, Cluj Napoca). 

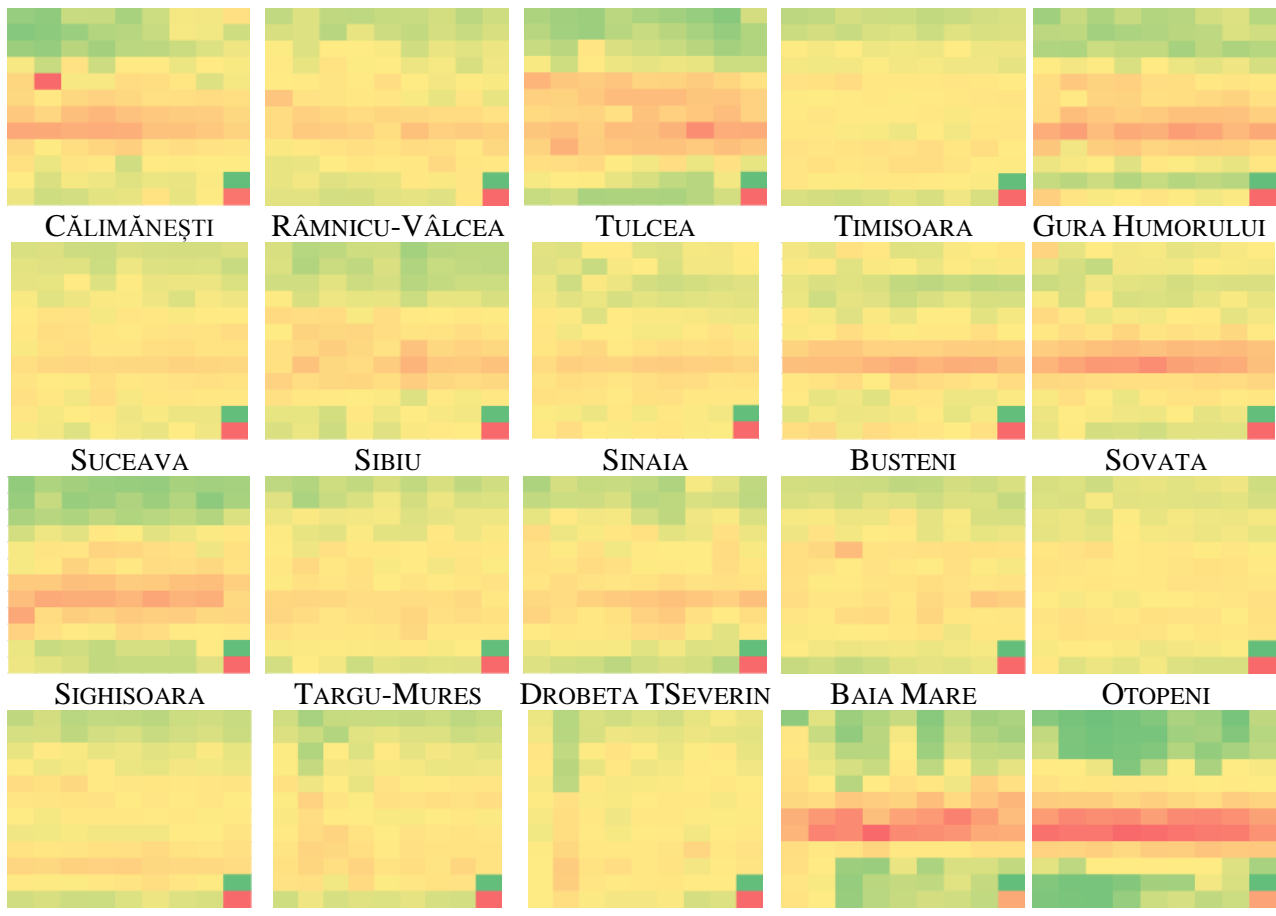

TARGU-MuRES
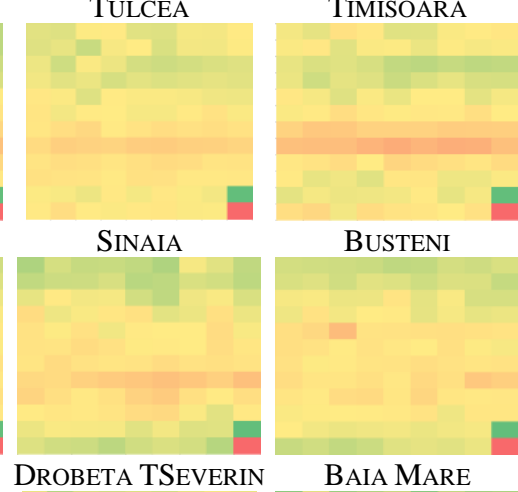

GURA HUMORULUI
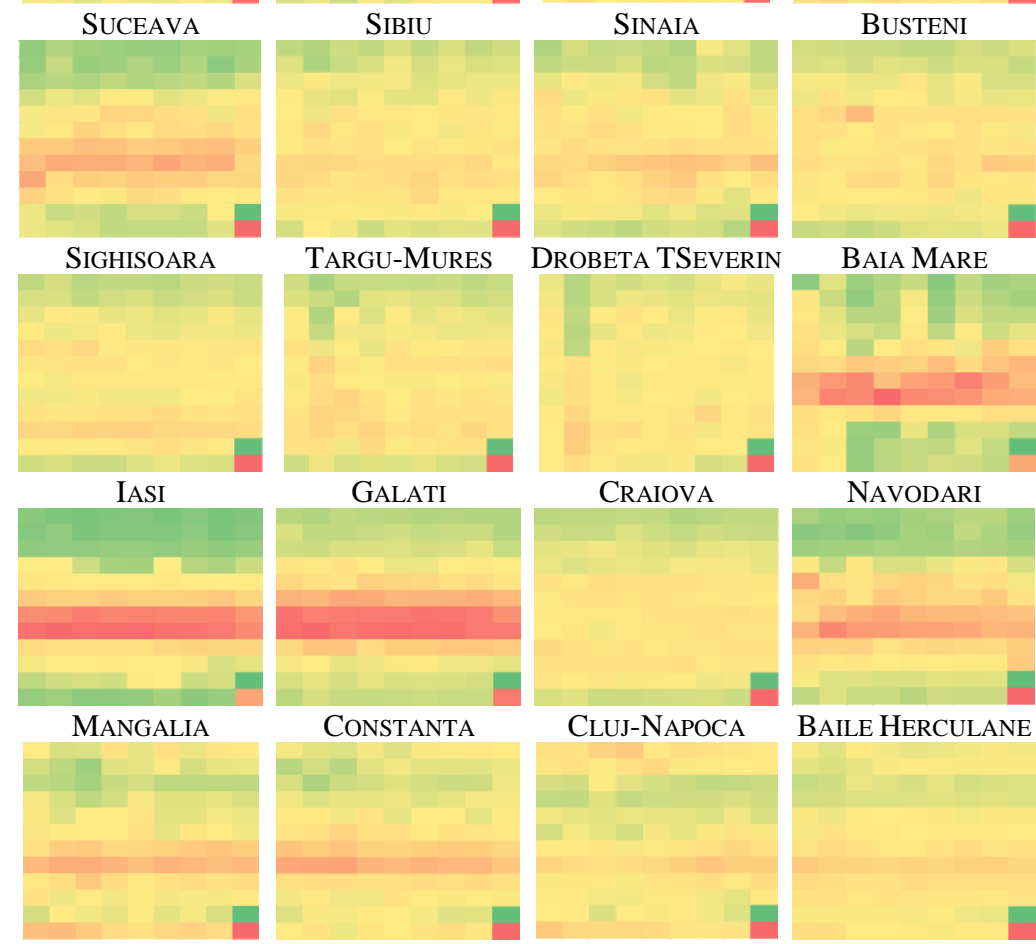

SovATA
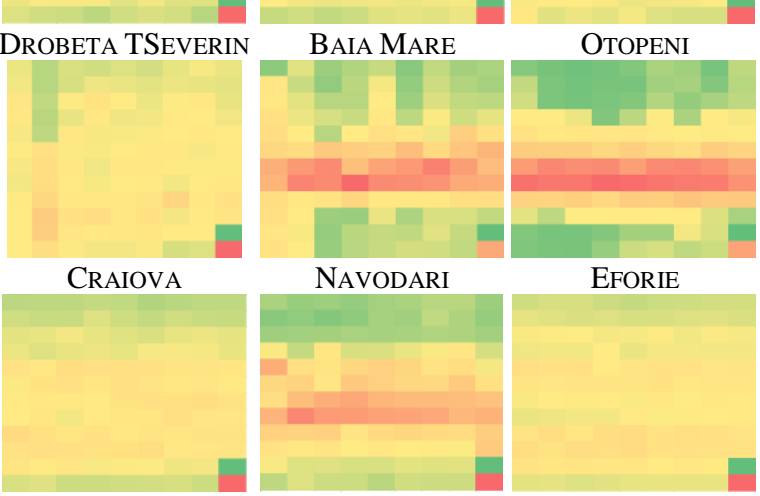

EFORIE

MOIECIU

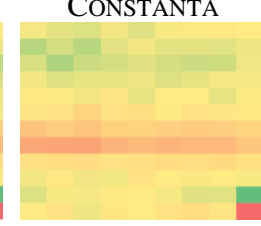

Cluj-Napoca

Baile HeRCUlane
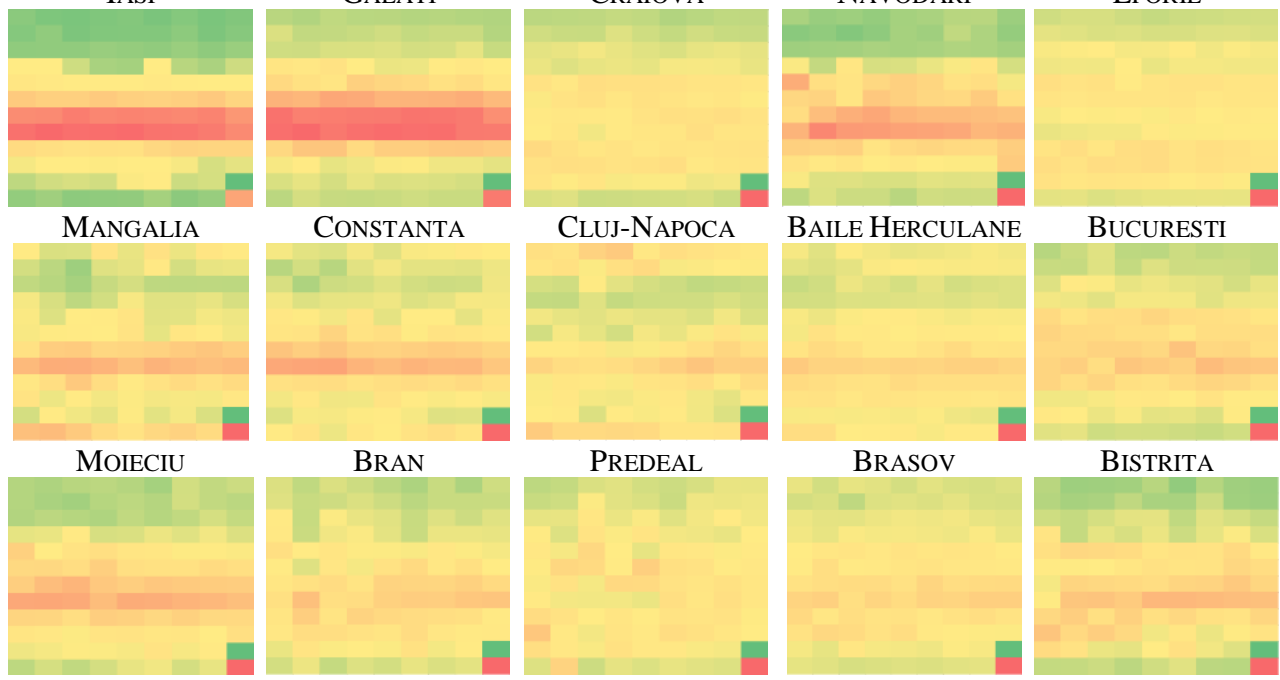

BRAN
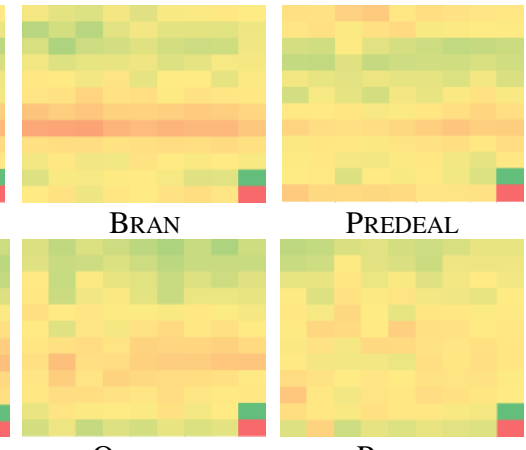

PREDEAL

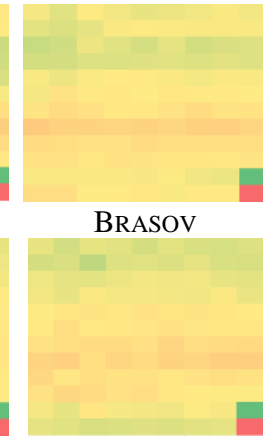

PItesTI

ARAD

AlBa IUlia

Fig. 2. Monthly seasonality over years (row - months, col.- years starting from 2010)

In the next step, all temperature data series were transformed in time series, decomposed in seasonal, trend and residual components (eq. 2). By visualizing the trend component for all places, we can identify a trend for all three temperature categories (daily minimum, maximum and mean). By applying the Mann Kendall 
test for all cases the null hypothesis was rejected enforcing our expectations that there are linear trends in data series (Fig. 3).

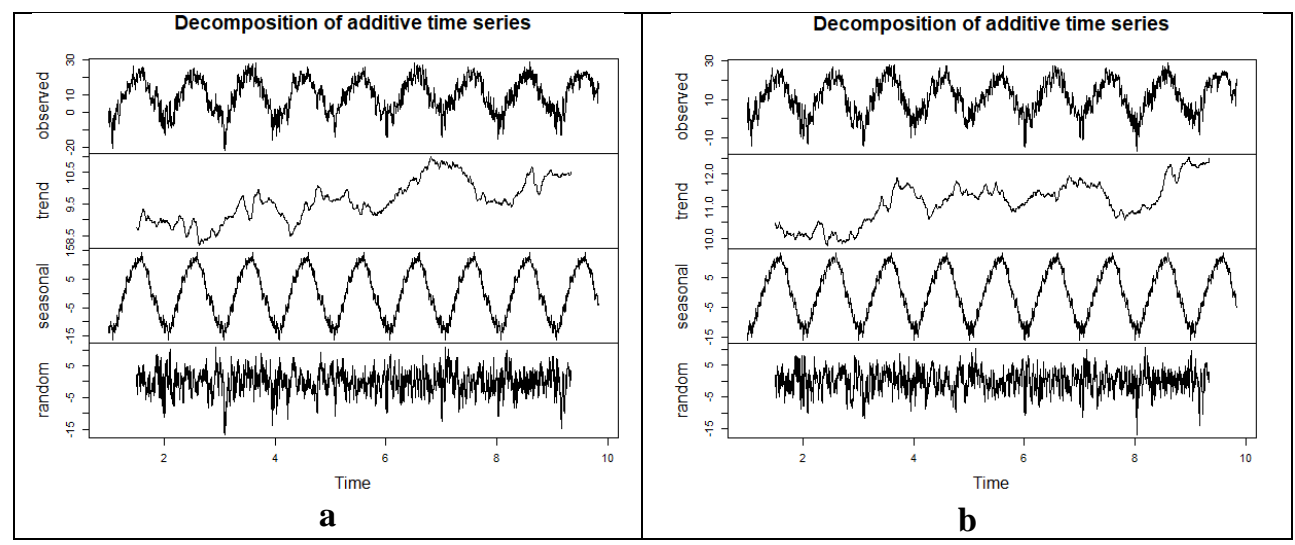

Fig. 3. Time series decomposition observing trend a) Suceava daily mean; b) Alba Iulia daily mean

$$
y_{t}=T_{t}+S_{t}+I_{t}
$$

where

$\mathrm{y}_{\mathrm{t}}$ is the time series,

$\mathrm{T}_{\mathrm{t}}$ the trend component,

$\mathrm{S}_{\mathrm{t}}$ the seasonal component and

$\mathrm{I}_{\mathrm{t}}$ the irregular (noise) component.

We do the same trend test also for summarized temperature values, using the seasonal variant of the Mann-Kendall test, as the correlation analysis which has to be followed was based on monthly values. In this case trend was detected as show in Fig. 4. The monthly average values of daily mean values at monthly scale have trend in $100 \%$, followed by the minimum values of daily mean values. In case of maxima of daily maximum, no trend appears.

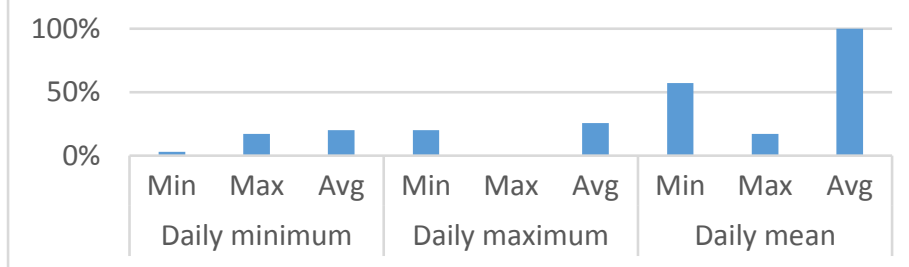

Fig. 4. Percent of locations where trends can be detected for different summarization of daily temperatures

Considering that temperature values has much or less changes for all places, the following step was to quantify if exist any relationship between seasonality change (or stationarity) and temperature. We calculated the correlation between seasonality indicator and the 9 temperature-related values, namely minimum, maximum and average values for daily minimum, maximum and mean values. Because the linearity of the relation cannot be supposed, we calculated both Pearson and Spearman correlation. The 
correlation was calculated for 106 data pairs, the $95 \%$ significance thresholds is 0.195 in case of Pearson and 0.197 in case of Spearman correlation for 100 data pairs. As seen from Table 1, linear correlation over 0.8 can be observed for 15 out of 35 places and if we consider also non-linear relationship the number of related locations rises to 19 and the relationship strengthen, in both cases far over the thresholds values.

Table 1. Correlation between temperatures and seasonality indicator

SPEARMAN RANK CORRELATION

PEARSON CORRELATION

\begin{tabular}{|c|c|c|c|c|c|c|c|c|c|c|c|c|c|c|c|c|c|c|}
\hline & & & & & & & & & & \multirow{2}{*}{\multicolumn{3}{|c|}{ Daily minimum }} & & & & & & \\
\hline \multirow{2}{*}{ Settlement } & \multicolumn{3}{|c|}{ Daily minimum } & \multicolumn{3}{|c|}{ Daily maximum } & \multicolumn{3}{|c|}{ Daily mean } & & & & \multicolumn{3}{|c|}{ Daily maximum } & \multicolumn{3}{|c|}{ Daily mean } \\
\hline & Min & Max & Avg & Min & Max & Avg & Min & Max & Avg & Min & Max & Avg & Min & Max & Avg & Min & Max & Avg \\
\hline Alba Iulia & 0.78 & 0.82 & 0.81 & 0.82 & 0.79 & 0.83 & 0.81 & 0.81 & 0.82 & 0.79 & 0.82 & 0.81 & 0.82 & 0.80 & 0.83 & 0.81 & 0.80 & 0.82 \\
\hline Arad & 0.83 & 0.86 & 0.88 & 0.86 & 0.86 & 0.88 & 0.86 & 0.86 & 0.88 & 0.81 & 0.85 & 0.87 & 0.86 & 0.85 & 0.87 & 0.85 & 0.85 & 0.87 \\
\hline Baia Mare & 0.82 & 0.81 & 0.84 & 0.82 & 0.82 & 0.84 & 0.82 & 0.81 & 0.84 & 0.80 & 0.78 & 0.81 & 0.79 & 0.81 & 0.82 & 0.80 & 0.79 & 0.82 \\
\hline Baile Herculane & 0.89 & 0.90 & 0.91 & 0.90 & 0.88 & 0.90 & 0.90 & 0.89 & 0.91 & 0.85 & 0.86 & 0.88 & 0.87 & 0.83 & 0.88 & 0.87 & 0.86 & 0.88 \\
\hline Bistrita & 0.89 & 0.90 & 0.91 & 0.90 & 0.89 & 0.91 & 0.90 & 0.89 & 0.91 & 0.86 & 0.89 & 0.89 & 0.89 & 0.86 & 0.90 & 0.87 & 0.87 & 0.90 \\
\hline Bran & 0.66 & 0.69 & 0.71 & 0.66 & 0.66 & 0.70 & \begin{tabular}{|l|}
0.67 \\
\end{tabular} & \begin{tabular}{|l|}
0.68 \\
\end{tabular} & 0.71 & 0.64 & 0.67 & 0.68 & 0.64 & 0.62 & 0.67 & 0.64 & 0.65 & 0.68 \\
\hline Brasov & 0.53 & 0.59 & 0.58 & 0.56 & 0.57 & 0.59 & 0.54 & 0.56 & 0.58 & 0.51 & 0.58 & 0.56 & 0.52 & 0.51 & 0.55 & 0.51 & 0.54 & 0.56 \\
\hline Bucuresti & 0.54 & 0.59 & 0.56 & 0.54 & 0.55 & 0.54 & 0.52 & 0.56 & 0.55 & 0.66 & 0.67 & 0.65 & 0.62 & 0.65 & 0.65 & .64 & 0.65 & 0.64 \\
\hline Busteni & 0.51 & 0.53 & 0.55 & 0.50 & 0.50 & 0.53 & 0.52 & 0.50 & 0.54 & 0.54 & 0.58 & 0.58 & 0.52 & 0.51 & 0.57 & 0.53 & 0.55 & 0.58 \\
\hline Calimanesti & 0.80 & 0.82 & 0.83 & 0.81 & 0.79 & 0.83 & 0.81 & 0.80 & 0.83 & 0.67 & 0.71 & 0.72 & 0.72 & 0.68 & 0.73 & 0.70 & 0.70 & 0.72 \\
\hline Cluj-Napoca & 0.71 & 0.73 & 0.72 & 0.72 & 0.68 & 0.72 & 0.72 & 0.69 & 0.72 & 0.80 & 0.81 & 0.80 & 0.79 & 0.79 & 0.82 & 0.80 & 0.79 & 0.81 \\
\hline Constanta & 0.96 & 0.93 & 0.96 & 0.96 & 0.93 & 0.97 & 0.97 & 0.93 & 0.96 & 0.79 & 0.80 & 0.82 & 0.82 & 0.76 & 0.82 & 0.81 & 0.80 & 0.82 \\
\hline Craiova & 0.42 & 0.44 & 0.43 & 0.42 & 0.43 & 0.42 & 0.43 & 0.42 & 0.43 & 0.42 & 0.42 & 0.40 & 0.39 & 0.40 & 0.40 & 0.42 & 0.39 & 0.40 \\
\hline Drobeta Turnu Severin & 0.81 & 0.83 & 0.84 & 0.80 & 0.81 & 0.83 & 0.81 & 0.83 & 0.83 & & 0.82 & 0.82 & 0.78 & 0.81 & 0.82 & .79 & 81 & 0.81 \\
\hline Eforie & 0.89 & 0.88 & 0.91 & 0.89 & 0.85 & 0.90 & 0.89 & 0.88 & 0.91 & 0.70 & 0.73 & 0.74 & 0.73 & 0.69 & 0.74 & 0.72 & 0.72 & 0.75 \\
\hline Galati & \begin{tabular}{|l|}
0.61 \\
\end{tabular} & 0.65 & 0.65 & 0.62 & 0.63 & 0.64 & 0.61 & \begin{tabular}{|l|}
0.63 \\
\end{tabular} & 0.64 & 0.69 & 0.70 & 0.71 & 0.68 & 0.70 & 0.70 & 0.69 & 0.69 & 0.70 \\
\hline Gura Hu & 0.81 & 0.80 & 0.81 & 0.81 & 0.79 & 0.81 & 0.80 & 0.80 & 0.81 & 0.76 & 0.78 & 0.79 & 0.78 & 0.74 & 0.79 & 0.77 & 0.76 & 0.79 \\
\hline Iasi & 0.57 & 0.61 & 0.59 & 0.58 & 0.59 & 0.57 & 0.56 & \begin{tabular}{|l|}
0.58 \\
\end{tabular} & 0.58 & 0.63 & 0.65 & 0.63 & 0.62 & 0.67 & 0.63 & 0.63 & 0.64 & 0.63 \\
\hline Mangalia & 0.95 & 0.94 & 0,96 & 0.95 & 0.92 & 0.96 & 0.95 & 0.94 & 0.96 & 0.68 & 0.70 & 0.72 & 0.71 & 0.67 & 0.72 & 0.70 & 0.70 & 0.72 \\
\hline Moieciu & \begin{tabular}{|l|}
0.44 \\
\end{tabular} & 0.46 & 0.48 & 0.45 & 0.42 & 0.47 & 0.46 & 0.43 & 0.48 & 0.43 & 0.47 & 0.48 & 0.44 & 0.39 & 0.46 & 0.44 & 0.44 & 0.47 \\
\hline Navodari & 0.82 & 0.79 & 0.82 & 0.83 & 0.80 & 0.83 & 0.83 & \begin{tabular}{|l|}
0.80 \\
\end{tabular} & 0.83 & 0.69 & 0.70 & 0.72 & 0.73 & 0.66 & 0.72 & 0.71 & 0.70 & 0.72 \\
\hline Oradea & 0.76 & 0.77 & 0.79 & 0.79 & 0.77 & 0.79 & 0.78 & \begin{tabular}{|l|}
0.76 \\
\end{tabular} & 0.78 & 0.76 & 0.77 & 0.78 & 0.78 & 0.76 & 0.78 & 0.78 & 0.76 & 0.78 \\
\hline Otopeni & 0.69 & 0.72 & 0.72 & 0.69 & 0.71 & 0.70 & 0.68 & 0.72 & 0.71 & 0.70 & 0.75 & 0.74 & 0.71 & 0.74 & 0.74 & 0.71 & 0.74 & 0.74 \\
\hline Pitesti & \begin{tabular}{|l|}
0.64 \\
\end{tabular} & 0.62 & 0.64 & 0.61 & 0.61 & 0.61 & 0.63 & \begin{tabular}{|l|}
0.61 \\
\end{tabular} & 0.63 & 0.63 & 0.59 & 0.60 & 0.58 & 0.57 & 0.58 & 0.61 & 0.57 & 0.59 \\
\hline Predeal & -0.04 & 0.02 & 0.02 & -0.01 & -0.02 & 0.02 & -0.01 & \begin{tabular}{|l|}
-0.02 \\
\end{tabular} & 0.01 & -0.04 & 0.05 & 0.02 & -0.04 & -0.06 & 0.00 & -0.04 & 0.00 & 0.01 \\
\hline Ramnicu Valcea & 0.82 & 0.83 & 0.85 & 0.81 & 0.82 & 0.84 & 0.83 & 0.82 & 0.84 & 0.80 & 0.81 & 0.82 & 0.79 & 0.80 & 0.81 & 0.80 & 0.81 & 0.82 \\
\hline Sanmartin & 0.87 & 0.86 & 0.90 & 0.88 & 0.86 & 0.89 & 0.88 & 0.86 & 0.89 & 0.83 & 0.83 & 0.86 & 0.84 & 0.80 & 0.84 & 0.84 & 0.82 & 0.85 \\
\hline Sibiu & 0.83 & 0.81 & 0.83 & 0.83 & 0.82 & 0.84 & 0.83 & 0.81 & 0.84 & 0.81 & 0.80 & 0.83 & 0.82 & 0.79 & 0.82 & 0.81 & 0.80 & 0.83 \\
\hline Sighisoara & 0.85 & 0.88 & 0.88 & 0.87 & 0.86 & 0.89 & 0.87 & 0.86 & 0.88 & 0.83 & 0.85 & 0.85 & 0.84 & 0.82 & 0.86 & 0.83 & 0.83 & 0.86 \\
\hline Sinaia & 0.54 & 0.60 & 0.62 & 0.54 & 0.58 & 0.61 & 0.54 & \begin{tabular}{|l|}
0.57 \\
\end{tabular} & 0.60 & 0.56 & 0.62 & 0.62 & 0.55 & 0.57 & 0.60 & 0.55 & 0.58 & 0.61 \\
\hline Sovata & 0.70 & 0.75 & 0.73 & 0.74 & 0.72 & 0.74 & 0.73 & 0.73 & 0.73 & 0.62 & 0.68 & 0.68 & 0.70 & 0.63 & 0.68 & 0.65 & 0.67 & 0.68 \\
\hline Suceava & \begin{tabular}{|l|}
0.82 \\
\end{tabular} & 0.83 & 0.83 & 0.83 & 0.81 & 0.84 & 0.82 & \begin{tabular}{|l|}
0.82 \\
\end{tabular} & 0.84 & 0.81 & 0.83 & 0.83 & 0.82 & 0.80 & 0.82 & 0.81 & 0.81 & 0.82 \\
\hline Targu-Mures & 0.75 & 0.80 & 0.78 & 0.78 & 0.79 & 0.79 & 0.77 & 0.78 & 0.78 & 0.78 & 0.81 & 0.80 & 0.79 & 0.80 & 0.80 & 0.79 & 0.78 & 0.80 \\
\hline Timisoara & 0.63 & 0.64 & 0.67 & 0.64 & 0.66 & 0.66 & 0.64 & 0.65 & 0.65 & 0.71 & 0.70 & 0.72 & 0.71 & 0.75 & 0.74 & 0.72 & 0.71 & 0.73 \\
\hline Tulcea & 0.86 & 0.88 & 0.88 & 0.89 & 0.87 & 0.89 & 0.88 & 0.87 & 0.89 & 0.85 & 0.883 & 0.888 & 0.884 & 0.864 & 0.898 & 0.872 & 0.868 & 0.894 \\
\hline
\end{tabular}

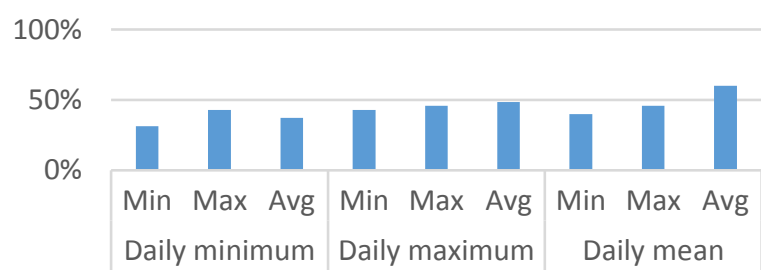

Fig. 5. Frequency of different summarized temperature values in best fit linear models

We defined a linear model for determining the seasonality value based on all 9 temperature components. Using a backward stepwise linear regression and AIC for 
evaluating the best model we counted how often different temperature component appears. The obtained result is presented in Fig. 5. We can observe that the monthly average value of the daily means has the highest frequency in all models followed by the average of maximum daily values and the maximum of minimum daily values.

The final step of our study was to observe the dynamics of linear correlation values for those 15 locations where the Pearson regression coefficient exceeds the 0.8 threshold value. For all these places, we plot the evolution of correlation coefficient for the highest ranked temperature component. We used two types of representation: a cumulative one starting from the end of the first year, and progressively calculating the correlation coefficient value for all past values (months) (Fig. 6), and the second for each past period of 12-month length (Fig. 7).

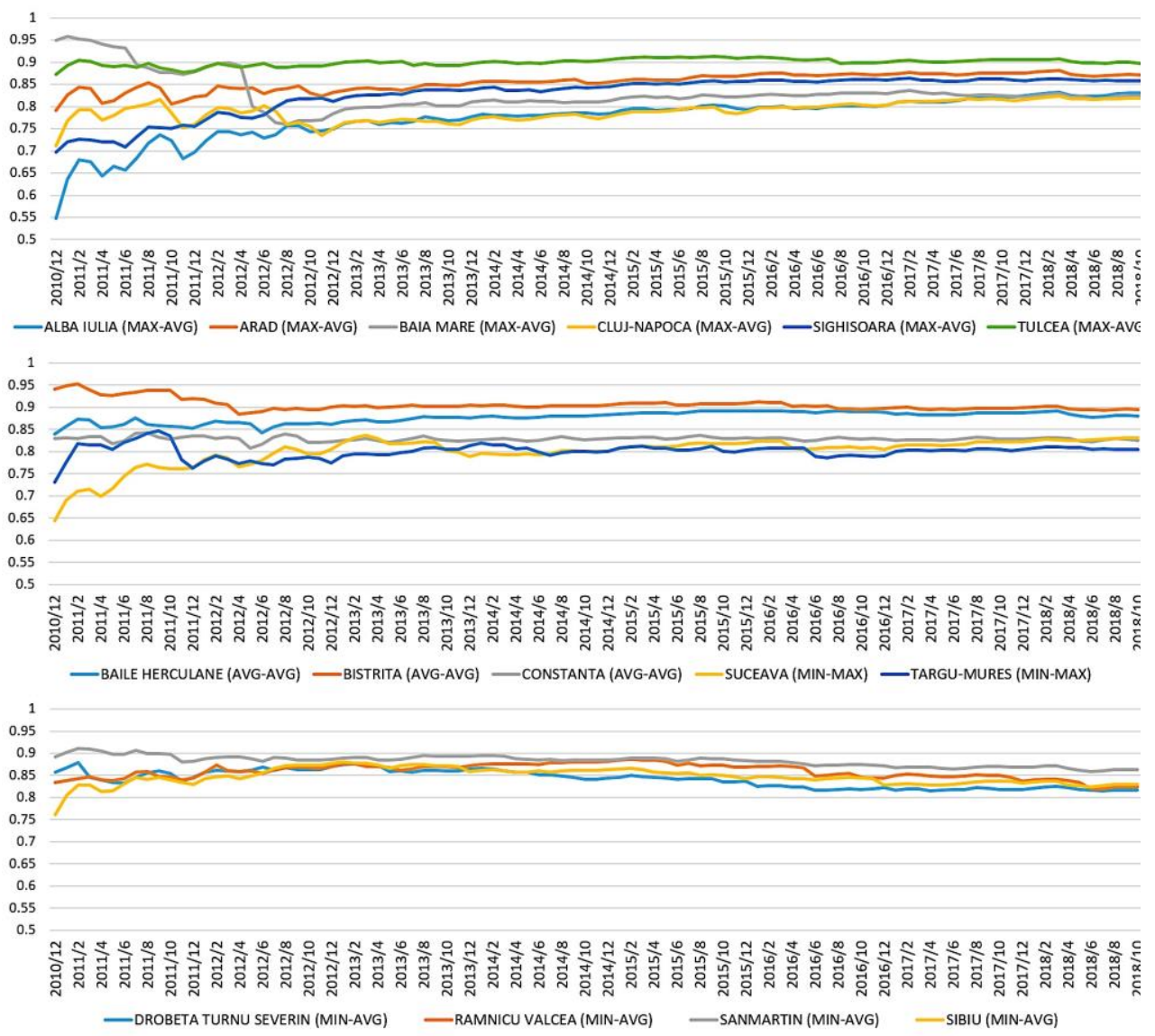

Fig. 6. Cumulative evolution of Pearson correlation coefficient

\section{CONCLUSIONS}

Temperature has a significant importance on tourism seasonality in Romania, yet not having the same impact on different places. In some cases, the monotonic correlation was more accentuated than the linear correlation, that's true mostly for the 
seaside places. Three temperature types were analyses, minimum, maximum and mean temperatures based on their daily values. The correlation between seasonality and various temperatures showed up that the most influential temperatures for seasonality are the average values of daily mean temperatures. Monthly extreme values (monthly minimum and maximum) have much less influence on tourism seasonality.

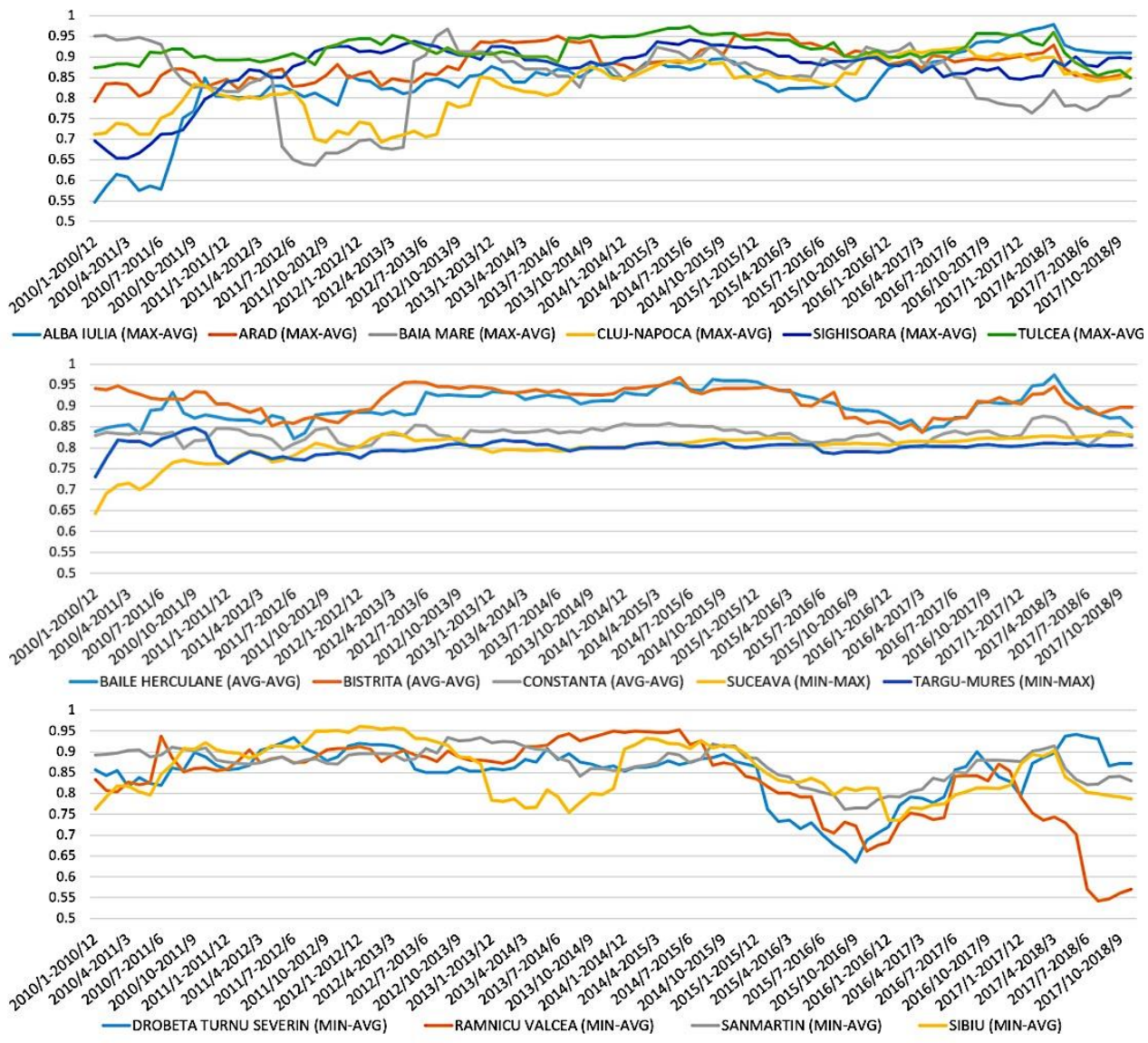

Fig. 7. Evolution of past 12-month length Pearson correlation coefficient

The mean temperature value is the most correlated with seasonality, followed by the maximum and finally the minimum temperature. The same order of importance was obtained for best fitting linear models describing seasonality. The high correlation values do not follow any spatial pattern regarding their spatial distribution. We found the same high correlation for Constanta having a high seasonality as for Arad, where seasonality is not accentuated (Fig. 8).

The dynamics of correlation is also varying. In general, for those places where the maximum temperatures resulted the highest correlation values a slightly increasing tendency can be observed. In those places where the average temperature caused the highest correlation the tendency of correlation is maintained, while where 
the minimum temperatures proved to be more important a slightly decreasing tendency in correlation coefficient variation is observed.

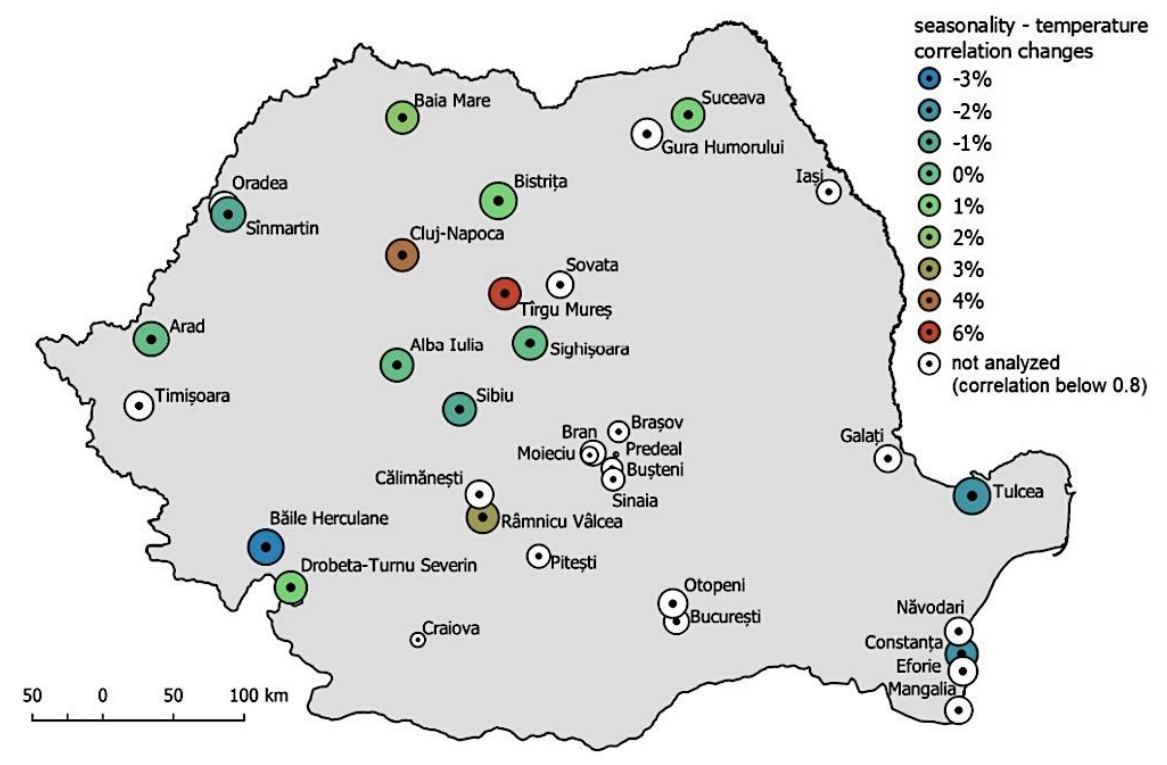

Fig. 8. Correlation values (proportional with radius) and its changes in the recent years (color scale) between temperature and seasonality

Although temperature is not the only factor influencing seasonality it seems to be a highly important one, as only 3 places from 35 selected ones the Pearson correlation coefficient stands below 0.5 . Further studies may investigate if there is a time lag that produces higher correlation values between temperatures and seasonality weather the tourist plan their trips in advance taking account the past years' temperatures or not.

\section{ACKNOWLEDGEMENTS}

We acknowledge the E-OBS dataset from the EU-FP6 project ENSEMBLES (http://ensembles-eu.metoffice.com) and the data providers in the ECA\&D project (https://www.ecad.eu)

\section{REFERENCES}

1. Bigovic M. (2011), Quantifying seasonality in tourism: a case study of Montenegro, Academica Turistica, Year 4, No. 2, pp. 14-32

2. Csapo J., Marton G (2017), The Role and Importance of Spa and Wellness Tourism in Hungary's Tourism Industry, Czech Journal of Tourism, 6, pp.55-68 
3. Corluka G., Vukusic A, Kelic I. (2018), Measuring tourism seasonality: application and comparison of different methods, Proceedings of the Conference: 4th International Congress TOURISM AND HOSPITALITY INDUSTRY 2018 TRENDS AND CHALLENGES, Opatija, Croatia April 26 - 27 2018, pp. 55-63

4. Dávid L., Baros Z. (2006): Impact of global climate change on tourism (in Hungarian), Gazdálkodás 15, pp. 82-91.

5. De Maio FG (2007), Income inequality measures, Journal of Epidemiology \& Community Health, 61 pp. 849-852.

6. Esterby, S.R. (1996), Review of methods for the detection and estimation of trends with emphasis on water quality applications, Hydrological Processes, 10, pp.127-149.

7. Formby J.P., Smith W.J., Zheng B. (1999), The coefficient of variation, stochastic dominance and inequality: A new interpretation, Economics Letters, 62, pp. 319-323.

8. Gallarza, M.G., Saura, I.G., Garcia H.C. (2002), Destination Image: Towards a Conceptual Framework. Annals of Tourism Research, 29. (1), pp. 56-78

9. Gonda T. (2017), From the "landscape eater" to the conscious tourist (in Hungarian), PTE KPVK, University of Pecs, p. 128

10. Gilbert, R.O. (1987), Statistical Methods for Environmental Pollution Monitoring, Wiley, NY.

11. Grizane T. (2016), Measuring Tourism Seasonality in regions of Latvia, Proceedings of the 2016 International Conference "ECONOMIC SCIENCE FOR RURAL DEVELOPMENT" No 42 Jelgava, LLU ESAF, 21-22 April 2016, pp. 59-64

12. Haylock M.R., Hofstra N., Klein Tank A.M.G., Klok E.J., Jones P.D., New M. (2008), A European daily high-resolution gridded dataset of surface temperature and precipitation. Journal of Geophysical Research (Atmospheres), 113, D20119, pp. 1-12

13. Höppe, P. (1997), Aspects of Human Biometeorology in Past Present and Future. International Journal of Biometeorology 40. pp. 19-23

14. James D., Hornik K., Grothendieck D. (2018), $R$ package, URL https://CRAN.Rproject. org/package $=$ Kendall

15. Karamustafa K., Ulama, S. (2010), Measuring the seasonality in tourism with the comparison of different methods, EuroMed Journal of Business, Vol. 5 Issue: 2, pp.191-214

16. Kulendran N., Dwyer L, (2012), Modelling Seasonal Variation in tourism flows with climate variables, Tourism Analysis, 17, pp. 121-137

17. Lundtorp S. (2001). Measuring tourism seasonality. In T. Baum, \& S. Lundtorp (Eds.), Seasonality in tourism. Oxford, Pergamon, pp. 23-50

18. Matsarakis A., Mayer, H. (1997), Heat Stress in Greece. International Journal of Biometeorology 41. pp. 34-39.

19. McLeod A.I. (2015) R package, URL https://CRAN.R-project. org/package=Kendall

20. Myers, R. H., \& Myers, R. H. (1990), Classical and modern regression with applications (Vol. 2). Belmont, CA: Duxbury press

21. Petrevska B. (2013), A simple test for the presence of seasonality in tourism in Macedonia. In: 1st International Conference "Regional Economic Cooperation in the process of Globalization", 6-7 Dec 2013, Tetovo, Macedonia, pp. 120-128

22. Pierce D. (2012), R package, URL https://CRAN.R-project. org/package=ncdf4

23. Pórhallsdóttir G., Ólafsson R. (2017), A method to analyse seasonality in the distribution of tourists in Iceland, Journal of Outdoor Recreation and Tourism, 19, pp.17-24

24. Puczkó, L., Rátz, T. (2005): Effects of tourism (in Hungarian), 4. edition; Aula Kiadó, Budapest

25. Trapletti A., Hornik K, LeBaron B (2018), $R$ package, URL https://CRAN.R-project. org/package $=$ tseries 
26. Tsitouras A. (2004), Adjusted Gini Coefficient and 'Months Equivalent' Degree of Tourism Seasonality: A research note, Tourism Economics, vol. 10, Issue 1, pp. 95-100

27. Uddameri V. (2017), Using $R$ to read NetCDF Files, WateR - R for Water Resources, DOI: $10.17605 / \mathrm{OSF} . \mathrm{IO} / 8 \mathrm{XCHE}$

28. Zeileis A., Kleiber C. (2015), R package, URL https://cran.r-project.org/package=ineq

\section{APPENDICES}

\section{Appendix 1 - Data sources and data extraction process}

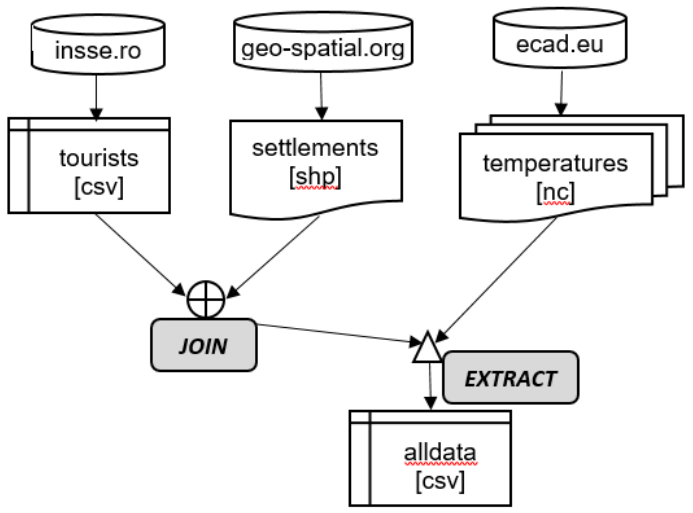

\section{Appendix 2 - Temperature data retrieval from netCDF file using $R$ script}

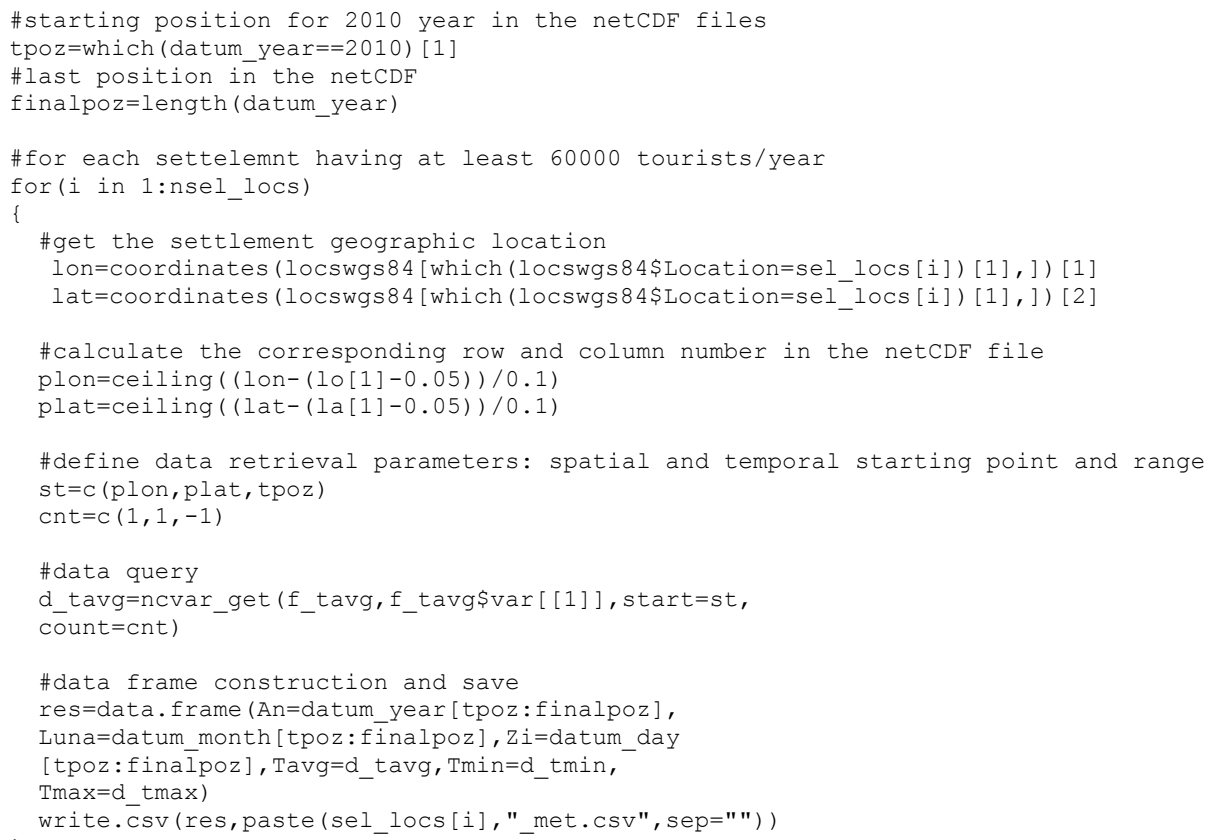

